Kohl: a Journal for Body and Gender Research

Vol. 3, No. 2 (Winter 2017)

\title{
Sexual Processes: Conversations Undone Amongst Queer Tunisian Women
}

\author{
Aslan, Masha, Layla, Feryal, and Dorra
}

Sex is impervious to reason, they say: primal, animal, and hollow. We learn that sex for enjoyment is selfish, and selfless in love and reproduction. We learn that sex is shallow, but that a sexless love is doomed with despair. Yet sex does not exist in a vacuum, it does not float above our heads, free of what grounds us. It often reflects and responds to our politics and ideas of the self and the other.

To which extent are our sexual preferences constructed, and can we ever claim that we have exited the realm of the imposed, by being queer, having sex, or abstaining from it?

This informal conversation was had on a Tunisian beach, on July 13 and 16, 2017, and lasted for a total of three hours. Five Tunisian women, four of whom are queer, discussed their sexual "coming-of-age" and their perceptions of desire and disgust. These excerpts surely do not represent an imagined community of Tunisian women, queer or straight, nor do they claim to do so. This conversation's best hope is to provide glimpses of an ecosystem that assembled our understanding of what sex and pleasure are, or what they mean to us.

Pseudonyms were used to protect the identity of the women who participated in this conversation. 


\section{On Discovering Sex}

Feryal: $\quad$ It is strange, I do not have an earliest memory of hearing about sex. But I think perhaps in middle school, when boys started using curse words such as cock and pussy, or motherfucker, was when I started thinking of sex as something negative. The first porn I saw was when a guy in my class told me that he watched +18 television channels, while we were only allowed to watch programs suitable for a younger audience. He told me to tune in to Multivision channel. There, I watched American Pie. While it was not pornographic, it was very explicit. Back then, we only rented DVDs or video cassettes. This was before the time we started using Canadian IP addresses to access porn. So, American Pie was the most readily available pseudo-porn that we could get our hands on as teenagers. Up until high school, I thought of sex as something ugly, something the perverts did. I did not imagine that my parents had had sex. It was like the idea of zina'. ${ }^{1}$ Then I started researching about sex.

Layla: I find it odd that something so negatively portrayed would incite research. I think there must have been something intuitive, a sort of innate moral compass that would make us reject these preconceived ideas. Although the analogy might be a stretch, perhaps when people hear preconceived ideas or negative propaganda about ethnicities or religions they do not belong to, they would not be so quick to question that knowledge, you know? Their interest would be averted. But when it comes to sex, no matter what is being said about it, it is not something avoidable, people do not necessarily have that luxury to not think about it. Well, unless they are asexual. Otherwise, sex is something that everyone is expected to take part in, so branding it as something to avoid would not be successful. Like, why did it spark an interest in you, if it was exclusively associated with the ugly and rude? Society tried so hard to tell you it is something meant for the perverts, and yet, instead of closing that topic, you were attracted to it.

Feryal: $\quad$ Because I wanted to belong. I never understood the use of the word "slut" until high school, when I looked at a guy and told him he was one. He laughed at me, saying it was not a word one uses for men, and I had made a fool of myself. It seemed like everyone was talking about sex, whereas I did not even know what it meant.

Layla: $\quad$ So, you ended up engaging in using slurs that were meant to put down women who are explicitly interested in sex, women like yourself, in an effort to belong.

Feryal: $\quad$ Yes. Other than American Pie, rappers like Eminem, 50 Cents, Snoop Dog, and Dr. Dre have also constructed my teenage idea of sex. When I got into high school and got my own PC, I started watching porn. This is when I discovered that I was masturbating all these past years, but I did not know what I was doing. I discovered masturbation in the shower. And then it did not cause me a moral panic. You know, my father had died, so when I learned about sex, it was something that my mother no longer did. It was

\footnotetext{
${ }^{1}$ Sexual acts considered immoral, such as adultery, sex outside marriage, and sex work.
} 
something in her past, distant from our lives. It was something done outside of our family. I kept wondering how she could live without it, since she has been celibate since she was 35 , and she is now 52. That is a whole lot of time. She is conservative and religious, and I do not even know if she masturbates, even though sexual activity is associated with youth and health in her mind. My mother's friends for example talk about how women who "do not get married" age faster. They would say a woman looks sick and older than her years because she is single. When I was younger, I thought to myself that it didn't make sense, that cooking and cleaning after a man would age her more. What they meant is that sex keeps women young, but not only sex, perhaps companionship as well.

Aslan: I do not remember a precise memory, but it was around middle school as well when I started hearing curse words. I asked my mother what "fuck you" meant. She said it meant to have intercourse, which is the sexual procedure that your parents do so they can have you. She told me about the egg and the sperm, centered it in reproduction. A very standard answer. I asked her whether she and dad always fucked and whether I could fuck as well. She said yes, married people do fuck, but no, I could not fuck because I was too young. She also added that we generally do not fuck in Tunisia because we are Muslim, and we cannot fuck arbitrarily; when people want to fuck, they go and get married. "But don't people get married when they love each other?" I asked her. She said that when they love each other, they also would want to fuck. She also explained the mechanics of sex in relation to reproduction. It was very heteronormative of course. So, I wanted to watch it. I had heard about the practice and wanted to see it, wait till my parents fuck and surprise them. I thought about eavesdropping or peeping from outside their bedroom door. But I could not catch them. I was never successful. Luckily, on a Saturday night on M6, I accidentally saw a porn movie that my father was watching. It was shocking at first; I was not thinking about the pleasure that could come with sex, I was mostly concerned with the aesthetics of it. When we went to the town where my grandfather lived, I missed watching porn since I was used to doing so regularly. So, I went downstairs to see if I could catch my father watching porn. To my surprise, it was not my father I caught, but my grandfather, who was a man of religion. When my father watched porn, I did not think of it as sinful, since he was married, so watching or doing was the same thing to me. So I started watching porn with my grandfather without him noticing. When I got tired of going downstairs every time, I told the family that his room was colder and that I wanted to sleep there. I used to sneakily watch porn with him on Multivision channels 6, 7, and 8.

Masha: $\quad$ During my adolescent years, I was very heteronormative since all the sexual discoveries I made were not educational; they were neither coming from my family nor from school, so it was both outside traditional and formal education. I gathered my knowledge from pornography and from the street. But it was not a discovery. Through the questions that we ask as children, I had always known about sex, but there had always been something secretive that was intimate, yet expected and inevitable. It was not something forbidden, but simply postponed until better times, when we got older. There were no negative 
connotations with the practice; of course there was the idea that women needed to preserve their virginity, but it was also mostly about postponing sexual activity, not withholding from it.

Dorra: $\quad$ My parents are medical doctors, so I do not have an earliest memory of sex. It seems as if I have always known about it. We talked about everything related to the body. My parents would come home from conventions with female and male condoms. Sexuality was portrayed as something that inevitably exists with the human body, not as something that must be hidden, although it was not a conversation we would have about the personal. It was mostly about avoiding predators - "don't let anyone touch you," "if somebody shows you their private parts, tell an adult," "if somebody touches you, it is not your fault, do not be afraid to tell us" - but not about the practice itself, or about pleasure. As children, our parents would ask us to protect ourselves from pedophiles, and as teenagers, to protect ourselves from pregnancy. Of course, they thought of sex heteronormatively. But at age eighteen, I was watching Next LGBT, a show on MTV, where people were asking each other out, then the couple who succeeded at building a relationship won. And that was when our parents started talking to us about the "East and West;" that was when they would interrupt us, asking us to bring a glass of water, the same strategy they employed when we watched violent scenes on TV. I did not come out to my parents, there was no need to. They know about it, and their concern is not the sex, but society - that I would have to beware of people.

\section{On Masturbation, Periods, and Porn}

Layla: I was wondering, Feryal, do you consider that your mother does not have a sexual life, since she does not have a partner? What about masturbation? Would you consider that someone who masturbates does have a sex life? Or do you view it as inferior to sex?

Feryal: I do not think that women my mother's age and from her background think of purposefully stimulating their genitals. Or, if they do, I do not think they understand it as masturbation, as a practice through which they can explore their bodies and satisfy themselves. They might touch themselves in the shower, but that would be a part of a hygienic ritual, or even a massage. They would not frame it to themselves as something sexual. Or else, if they feel horny, they would distract themselves with something else. I know it from myself, I start eating.

Dorra: I think masturbation is about self-discovery more so than about sex. Sex is about mutuality, discovering yourself and others. It could also be about non-physical intimacy, like sexting or cyber-sex, which would incite people to masturbate or fantasize. Some people get turned on by a conversation alone. Of course, you run the risk of having the person on the end of the line being there for laughs, not for sex; you would not know their intention and whether they are pranking you or performing what they say they are. But at the end of the day, it serves its purpose if you got pleasure out of it. 
Masha: I do not think sex is a life need. It is a physiological one, not like others in that triangle, not like food and drinks and defecation, but more like entertainment. You need it because you need fun, not because you need to survive and your body cannot function otherwise. The concept of desire is distinct from giving or receiving pleasure. When you give, you are not physically experiencing pleasure. You are not stimulated like that. As a queer woman, I was told I give the best cunnilingus in Tunis. And one of my most pleasurable moments was penetrating a man. It was not necessary for me to orgasm, but I got pleasure out of it. I wanted to live that role, not necessarily that of a man, but based on the history of heteronormative expectations, I desired the opposite of what society expected from me. I did not wait for a partner to discover myself; I took my time with myself, with masturbation. The best experience of self-discovery. It allows one to know what they like and what they want.

Feryal: $\quad$ Growing up, I thought of there being two kinds of sex: one that is polite and reproductive, meant for marriage, and another dirty and aggressive that perverts had. I didn't know where masturbation fell.

Layla: $\quad$ It is kind of like that, if you think in terms of sexual hierarchies.

Feryal: $\quad$ I also had the idea that there are women who are meant for consumerist sex, and nothing more. I had the readily made value judgement, so when women were put down in front of me for their explicit sexuality, I did not intervene; it seemed like a logical consequence. So, when people cursed, they were referring to the rude sex, not the one parents had. I even thought that these types of sex are distinct in terms of the positions, that there is a Kamasutra for the polite and married, and one for the perverts.

Layla: It is still kind of true, as vaginal sex is "polite" and anal is not, in heteronormative relationships. Or that discourse on men going to sex workers because their wives would not perform something "perverted" like blowjobs. So, were you polite or impolite when you were masturbating? For example, in my teenage years, I identified with the perverts, because my sexual practices were not in line with the fairytales of love, marriage, and reproduction.

Feryal: $\quad$ I have not thought about it. It was something pleasurable that did not bring me shame. It wasn't very regular. I did not think of it as masturbation. Even when I had my period, I didn't understand what it was until we studied it in high school. I remember that I got my first period in primary school and went running home telling my mother that there was blood in my underwear. She looked confused and gave me a pad. She did not explain anything. That day, she avoided me. Perhaps she was shocked that her daughter had grown. And that is what she told me later, that I had grown, without any other explanation.

Layla: I learned about sex in primary school. I went to a primary private French school, and there were drawings of penises and vaginas on the wall, with arrows that showed where 
the penis should go. It seemed illogical. I did not know why anyone would do that: why would men push their penises inside women? It seemed invasive. And then with the whole culture of covering up, I did not know why women would remove their panties to allow this to happen either. My mother had talked to me about sex before, about the grain that travels to the belly and things like that, but she had omitted the part where a penis penetrates a vagina. I guess I imagined that the grain traveled through the saliva, another bodily fluid, since I had seen people kiss. So, when I saw the drawings with the arrows, it broke the trust I had in my mother - how could she bypass telling me something like that? She was lying by omission. The tale of love and grains suddenly became violent.

Aslan: In my teenage years, I felt that I was more entitled to ask my mother about sex, as inevitably, we'd be talking periods, pads, and pains, at least in terms of the regularity of the period and whether I was "healthy" or not. I remember that our neighbor, who served as minister of women's affairs at some point, gave me a book at age 12 about women in their biological functions of reproduction. I remember feeling that my knowledge had expanded, that I moved to a different stage of life. For example, I asked my mother why people scream when they fuck, and she said it was because of orgasm. Then she remembered and asked me where I had heard people fucking.

Feryal: $\quad$ When I was watching One Tree Hill, there was a scene where 5 friends were having a sleep over, including two couples, and one single girl whose name was Brook. When Brook was alone in the room masturbating, her friends asked her if she was "brooking herself." They did not say the word masturbation. So, I thought the proper terminology was "brooking yourself." When I started watching porn, I learned the actual terminologies, not the euphemisms.

Aslan: I read about masturbation being a sin, so it meant that it was something zabbour, ${ }^{2}$ and that was what made me want to do it.

Dorra: $\quad$ The problem with porn is private property. It is an industry, like any other, where the owners want to make money based on the fantasies of the men who pay. So, it is men who dictate the market. It is a dictatorship. You can't project yourself in the video, but you can still find something for yourself.

Aslan: I started watching porn regularly with my friends when our parents were not home; we would make a gathering out of it. Instead of going out and playing hide and seek, we would stay in and browse the Hotbird channels. And that was when we watched lesbian porn. My friends started saying things such as "ewww, women together, that's a sin."

Layla: $\quad$ But watching people fuck is not?

\footnotetext{
2 Tunisian slur, meaning "cunt" or "extremely sexy" depending on the interlocutor: inappropriate for common use, though appropriated in some women circles.
} 
Aslan: I have not given it much though. Maybe because watching was harmless, it did not hurt anyone, or break any rule. Well, you know, there is no verse in the Qur'an that could be interpreted as a forbiddance to watch porn, I think. Despite my mother's definition of sex being between men and women, I knew that the women in lesbian porn were having sex, not a different practice, despite it not being the definition I learned. I was convinced that practicing it was a sin, but not watching it, since it does not involve cheating or reproducing. I was comfortable with myself and my religiosity.

\section{On Body Image, Fantasies, and Attraction}

Layla: $\quad$ For me, having sex gave me comfort with myself. Before I had sex, I did not know that my body was attractive. I know it sounds wrong because sex is no measure of attractiveness, but growing up and seeing that women in porn had very standard vulvas that did not look like mine at all was disheartening. Porn did not liberate me. I was always worried that there was something wrong with my body, aesthetically, and in terms of its fuckability. So, when I started fucking, it reconciled me with my body.

Feryal: $\quad$ And you knew you were a zabbour.

Layla: I I was always harassed on the streets, but harassment did not mean I was attractive; it also meant that there was something off about my appearance, that my body had let me down. Fucking was different because it was consensual. I invited people to the act; they did not simply claim ownership or entitlement over my body because it was passing them by in the public sphere.

Feryal: I understand about the bodily insecurity. I wanted to bleach my vulva with sodium bicarbonate, but then I learned that it burns the skin by coincidence, as a woman at work had done that. It kills the fauna. However, amateur porn has helped me find different body types with stretchmarks, etc. So, it helped me be reconciled with my body. I still compare myself to other women, but it is not like in the past. If I see a woman showing her stretchmarks, I immediately relax, my posture changes, and I feel more comfortable than I do around the pressure of a perfect-bodied person. It is not only empowering in my romantic relationships, but also in my friendships. I feel that people are more comfortable around me when I am more comfortable with my body and open about its sexuality.

Aslan: I remember when I was fantasizing, it was heterosexual intercourse that I would imagine, although my role was not necessarily that of a woman. And it used to confuse me. Why in the world was it that when I closed my eyes and imagined having sex, I would be the guy? So, I used to think that maybe I should be a guy.

Layla: $\quad$ I was also the guy! 
Aslan: $\quad$ That is so strange, I am only remembering this now.

Dorra: $\quad$ A non-conforming gender expression does not mean one is queer. It is more complicated now, with social media networks and dating applications that push you into a binary, as you must meet people based on their appearance. It is difficult to escape this setting.

Aslan: $\quad$ I have never thought about fucking a man. Maybe that was when my attraction to women started, even though I did not think about it that way. I would be able to aesthetically appreciate them, I guess, because it was a given that I would be imperatively attracted to a man. The first time I kissed a guy, it did not move me at all. I was disappointed; was that what we had always been looking for? This is it? This is what it is all about? I thought that maybe it was because I did not know how to kiss. So, I asked the girls if we could practice, and it turns out that they had already practiced among themselves. There was a certain double standard: that kissing girls is disgusting and sinful, but it is better than learning how to kiss from a guy. When we kissed, it was much better than my first kiss, even though it was coated with a layer of disgust.

Feryal: $\quad$ Bachata also helped me recognize my body as sexual. It is a community with different imperatives, ones that are not about covering and hiding. You are asked to emphasize your boobs and ass. Men are also requested to make their asses more prominent during the dance. There are different standards for what is right depending on what community we are talking about, but also depending on how much money one has. For example, my grandmother's sister-in-law was probably "intersex," as we understand it today. During that time, nobody knew what intersex was, and they used to refer to intersex persons as "mules," because mules do not reproduce. Despite the stigma, the woman was from a notable family, and because of her social class, it was more important for her husband's family to be related to hers than for them to have children.

Aslan: $\quad$ When I started studying at Beaux Arts, I met lesbians because many of them were visible in that setting. That was when I revisited my religion, and found that there were many interpretations pertaining to homosexuality. I no longer thought it was sinful. At the same time, I started seeing a man and got engaged to him, because my friends were getting married and it felt competitive, although I never experienced sexual desire towards him. I did not want to fuck him. In my head, I associated it with my religious upbringing rather than my sexual orientation. He did not want to fuck either, because he was conservative, and would not fuck the woman he would marry. My mother's first explanation of sex was about love, and therefore I thought that when our love became legal when we would get married, we could have sex. I decided to have non-penetrative sex with him but I could not reach an orgasm. There was a woman from my distant family who was also engaged to a man. We used to go on double dates. From the first day we started hanging out, I knew there was something special about her. We started hanging out alone. She would caress me and touch me. I thought that my other friends did not do that. 
Layla: $\quad$ Did you feel violated?

Aslan: $\quad$ No, it felt right. But it also felt strange and uncommon, mostly because I liked it a lot, and did not like it when my fiancé touched me. It was also confusing. Why would she touch me like that? I was maybe 26 when I realized I was a techa. ${ }^{3}$ She would tell me that she loved me, and I loved her too. But my others friends and I did not communicate that way. One day, she laid on top of me and said that she was unhappy in her relationship. I immediately imagined she was about to tell me she was a lesbian. But she did not do more. One day, we finally decided to spend a night in a hotel together. She said that the best part was that we would get to share the bed. At night, in a pub, two men were hitting on us, and she pretended we were lesbians so that they leave us alone.

Layla: $\quad$ That's a long shot.

Aslan: $\quad$ At night, we were almost glued to each other, talking about the sex we had with our fiancés. She asked me if I had ever cheated on mine. I said no. She said she had cheated on hers with a woman. Then she asked me if I was stupid or if I genuinely did not understand. I was still confused, so she expressed the desire to kiss me. We spent the night caressing each other, without having intercourse, but we both reached orgasm. When we were done, she asked me if we had committed a sin - she is homophobic, by the way. And I said no. We never spoke of it again.

\section{On Disgust, Desire, and Pleasure}

Masha: $\quad$ There are certain things that I do not practice, like scatophilia. For me to have sexual relations, I need a minimum of hygiene.

Layla: $\quad$ There is an assumption that some practices are more hygienic than others. One might not want to engage in kinky practices, but it does not mean they are disgusting or not "clean" enough, especially that most kinksters are well aware of basic safety precautions, more so than vanilla people I would add.

Masha: $\quad$ BDSM is not something I can give or receive, although I know that it is about consent. It is a psychological barrier that I have despite knowing that people are literally "asking for it." I went to workshops about BDSM to try and make peace with it, but I cannot handle violence.

Layla: Well, you know it is not violence. Violence is what is coerced on people.

\footnotetext{
${ }^{3}$ French Verlan, from "chatte" which means cat, or pussy. Used in inverse te-cha (instead of cha-tte) in Tunisia about sluts. Appropriated by some women in lesbian circles to describe their sexuality.
} 
Masha:

I am still unable to dissociate it from violence. But to me, only the simple mind does not evolve. People change and become more accepting with time. It could stop being associated violence for me as well. At this stage, I think it is extreme for me, but "extreme" is also relative, so it might not be to others.

Layla: It is possible to move from discomfort to understanding, and away from the discourse of "let them do whatever they want as long as they stay away from me." It is the same discourse that homophobes use to say that gay folk can keep it to themselves.

Dorra: I I fo find scat play to be disgusting, but I think the disgust is not instinctive; if it was about our instinct rejecting bodily fluids, then no one would have children because they would be disgusted by sperm. I think desire and disgust come from a place of pleasure. You would identify what's pleasurable to you and act accordingly. For example, some people have different sexual preferences in terms of physical appearance. When you are exclusively attracted to one "ethnic look," it becomes racist, as you are not interested in the person, but in their ethnicity. Have you watched Skins? It is about this man who is not in love with the person, but keeps looking for a certain formation that he fetishizes.

Layla: $\quad$ So, if I just want to just fuck, and I am not interested in the person, their hopes, and their dreams, I do not want to know anything about them, I just want to fuck and move on, is that bad? I am obviously not interested in the person, but does that make me shallow?

Dorra: $\quad$ The example with ethnicity is different; it is not about physical aspect like tall or short, but a racial evaluation of people. Desire is not rational. And pleasure is instinctive, something that is innate. Or is it?

Layla: $\quad$ Pleasure or desire?

Dorra: $\quad$ Pleasure.

Layla: I think it is not necessarily physical. When people with limited bodily ability have sex, they do not necessarily have it in an ability-centric way: people who have prosthesis, or trans women who do not use their penises for sex, and do not ejaculate. There is a different pleasure that is not necessarily biological. I could get pleasure out of someone sucking my strap-on. And that would be sexual pleasure that is not physical. There is no essentialist formula to desire and no generic recipe for pleasure. They stem from places of the concrete and the imagined, from memories, values, and fears. Desire and pleasure are disciplined by every superstructure we encounter. They are internalized, reproduced, challenged, and fought. They are all these things together: a dialectic. Talking about sex is a critical exercise, one that reminds us to question the granted, the reserved, and the postponed. Oftentimes, we are forced to wear identities associated with our sexual practices, as women, sluts, and queers, and we forget that the branding alone is a conversation undone. We need to continue these conversations. 